\title{
Amniotic Membrane Transplantation in the Treatment of Primary Pterygium: A Comparative Study of Two Techniques
}

\author{
${ }^{1}$ Reema Bansal, ${ }^{2}$ Arun K Jain, ${ }^{3} \mathrm{R}$ Sehgal
}

\section{ABSTRACT}

Purpose: To compare two techniques of human amniotic membrane transplantation (AMT) following pterygium excision: (1) end to end suturing of the amniotic membrane graft (AMG) with the conjunctiva versus (2) a new technique of purse-string suturing of the AMG and tucking of $A M G$ under the free edge of conjunctiva.

Materials and methods: Pterygium surgery with human AMT was done in 42 eyes with primary pterygium. Twenty four eyes (group A) underwent end-to-end suturing of AMG with conjunctiva. Eighteen eyes (group B) underwent purse-string suturing of AMG with underlying sclera with free edge of AMG tucked under conjunctiva on three sides. The two groups were compared in terms of the outcome measures, i.e. complete epithelialization time of AMG and recurrence of pterygium within 1 year.

Results: The complete epithelialization of AMG occurred in 21 days (range 14 to 28 days) and 14 days (range 7 to 21 days) in groups $A$ and $B$ respectively. In group $A, 7$ eyes $(29.17 \%)$ developed recurrence. In group B, 2 eyes $(11.11 \%)$ developed recurrence.

Conclusion: Purse string suturing and tucking of AMG resulted in faster epithelization of AMG and lower recurrences in comparison with end to end suturing of AMG in the management of primary pterygium.

Keywords: Pterygium, Amniotic membrane transplantation, Purse string suture technique, Inflammation.

How to cite this article: Bansal R, Jain AK, Sehgal R. Amniotic Membrane Transplantation in the Treatment of Primary Pterygium: A Comparative Study of Two Techniques. J Postgrad Med Edu Res 2014;48(1):1-7.

Source of support: Nil

Conflict of interest: None

${ }^{1}$ Assistant Professor, ${ }^{2,3}$ Professor

${ }^{1}$ Department of Ophthalmology, Advanced Eye Centre Postgraduate Institute of Medical Education and Research Chandigarh, India

${ }^{2}$ Department of Cornea, Cataract and Refractive Surgery, In-charge Eye Bank, Advanced Eye Centre, Postgraduate Institute of Medical Education and Research, Chandigarh, India

${ }^{3}$ Department of Parasitology, Postgraduate Institute of Medical Education and Research, Chandigarh, India

Corresponding Author: Arun K Jain, Professor Advanced Eye Centre, Postgraduate Institute of Medical Education and Research, Chandigarh-160012 India, Phone: +91-172-2747837, Fax: +91-172-2747837 e-mail: aronkjain@yahoo.com

\section{INTRODUCTION}

Successful management of pterygium is a constant challenge for ophthalmologists; recurrence rates range from 2.1 to $87 \%$ with different techniques. ${ }^{1,2}$ A wide variety of surgical techniques have been employed in the treatment of pterygium, with aim of getting good cosmetic results, lower recurrence rates and lesser complications.

The methods adopted include bare sclera excision, with or without the adjunctive use of Mitomycin C or $\beta$-irradiation or wound closure using a conjunctival autograft, ${ }^{3-7}$ conjunctival rotation autograft, ${ }^{8}$ conjunctival limbal autograft, ${ }^{9}$ conjunctival flaps, ${ }^{10}$ and more recently, human amniotic membrane transplantation (AMT). ${ }^{11-14}$ Adjunctive therapies such as beta irradiation, ${ }^{15,16}$ thiotepa or mitomycin- $\mathrm{C}$ have been proposed as means of reducing recurrence rates, but the side-effects of these options limit their use. ${ }^{17-21}$ It is speculated that the extent of excision during surgery, ${ }^{12}$ techniques, ${ }^{11}$ morphology of pterygium and the use of adjunctive treatment modalities influence the recurrence rates. ${ }^{20}$ Human AMT is associated with a very good cosmetic result, ${ }^{12}$ preservation of conjunctiva for future ocular surgery and a low recurrence rate ranging from 2.8 to $10 \% .^{11,12,20}$

In the present study, we have explored the use of human AMT by a new surgical technique of passing a purse string suture and tucking of the amniotic membrane graft (AMG) under the conjunctiva, and compared it with the conventional end to end suturing of the AMG with the conjunctiva. The outcomes, i.e. complete epithelialization time of AMG and recurrence of pterygium were selected a priori and specified before we started to look back at our cases.

\section{MATERIALS AND METHODS}

\section{Patients}

Forty-two eyes of 42 patients with primary pterygium were included from the cornea and external diseases clinic, Department of Ophthalmology, postgraduate Institute of Medical Education and Research, Chandigarh, from June 2002 to October 2003. They were retrospectively analyzed 
after obtaining ethical clearance from the Institute Ethics Committee. The study adhered to the tenets of declaration of Helsinki.

Written informed consent was obtained from all patients. This study included consecutive patients undergoing pterygium surgery with following inclusion criteria:

1. Grade $\mathrm{T} 2$ of primary pterygium (the form in which the underlying vessels are partially seen).

2. Grade T3 (fleshy form in which the underlying vessels are not visible). ${ }^{7}$

3. A minimum follow-up of 12 months in each group following pterygium surgery.

The exclusion criteria were: (1) Grade T1 (atrophic form in which episcleral vessels are visible through the body of the pterygium); (2) recurrent pterygia; (3) dry eye patients as evidenced by tear film break up time (TFBUT) of less than 10 seconds; (4) cicatrization of the conjunctiva as evidenced by presence of adhesions in the fornices; (5) patients less than 15 years of age.

The demographic profile of patients, preoperative examination (including pterygium severity, Schirmer test, TFBUT), surgical procedure, postoperative outcome, complications and recurrence were recorded. The length of the pterygium on the cornea and the width of the pterygium at the limbus were measured in millimeters preoperatively.

Patients were seen postoperatively on day 1, 3 and 1, 2, 3 weeks and 1, 3, 6 and 12 months. At each follow-up visit, visual acuity, tonometry and slit-lamp examination were performed. Fluorescein staining was used to assess the integrity of the epithelial surface.

\section{Surgical Procedure}

\section{Preparation and Preservation of Amniotic Membrane Graft}

Standard protocol was followed in the harvesting and processing of the amniotic membrane using Dulbecco's modified Eagle's medium (DMEM). ${ }^{22}$

\section{Pterygium Excision}

The surgical technique involved transplantation of human amniotic membrane to the exposed sclera after pterygium excision and securing it by two different techniques described below. All the procedures were performed by a single surgeon (AKJ) to ensure similarity in the procedure, thereby eliminating inter-surgeon variability.

Pterygium excision was performed after administration of peribulbar anesthesia. The local blocks consisted of a $6: 4$ mixture of $10 \mathrm{ml}$ of $2 \%$ lignocaine with $1: 20,000$ Epinephrine and $0.5 \%$ Bupivacaine. Under aseptic precautions, after inserting a lid speculum, two stay sutures
(6-0 vicryl) were passed on the $12^{\prime} \mathrm{O}$ clock and 6'O clock of the limbus and pulled temporally to expose the surgical area of interest. The pterygium was grasped with atraumatic forceps and a cut given with vannas scissors parallel to the limbus approximately $1 \mathrm{~mm}$ away toward the sclera and the subconjunctival fibrous tissue separated using blunt dissection as far as the canthus. The head of the pterygium on the cornea was removed using blunt dissection. The medial rectus muscle was identified before excising the fibrous tissue in the body of the pterygium so as not to damage it while removing the body of the pterygium. The bleeding vessels on the bed of the pterygium were cauterized to have bloodless field. The length and width of the excised area were measured with calipers. Amniotic membrane graft was brought to room temperature and the mesenchymal surface identified as the one sticking to the nitrocellulose paper. ${ }^{11}$

\section{Amniotic Membrane Transplantation}

Two different techniques were used for transplantation of the amniotic membrane. In group A (24 eyes), the AMG was first cut approximately $1 \mathrm{~mm}$ bigger than the size of the defect on the ocular surface and then sutured end to end with the conjunctiva using 10-0 monofilament nylon in interrupted manner (technique 1). In group B (18 eyes), after proper positioning of the AMG over the excised pterygial area, a purse-string suture was passed using 10-0 monofilament nylon through the AMG and superficial sclera tissue. Care was taken in passing the suture in the region of the medial rectus muscle in such a way the scleral bites were taken superior and inferior to the horizontal superior and inferior edges of the medial rectus muscle respectively and superficial bite of the suture remained on the surface of amniotic membrane in the region of medial rectus muscle. After tying the suture, the extra amniotic membrane was trimmed leaving approximately $2 \mathrm{~mm}$ of free edge of the graft that was then tucked beneath the free edges of the adjacent conjunctiva (technique 2 ) as shown in Figures $1 \mathrm{~A}$ to $\mathrm{C}$. Topical antibiotic drops (ofloxacin $0.3 \%$ ) were instilled and the eye patched.

\section{Follow-up}

Topical antibiotic-corticosteroid drops (4 times a day) and preservative free artificial tears (4 times a day) were prescribed postoperatively, tapered over one and a half month. The postoperative treatment regimen was identical in both groups of patients. Patients were followed up on day 1, day 3 and 1, 2, 3 weeks and 1, 2, 6 and 12 months. Detailed ocular examination was done on slit-lamp at each visit. Fluorescein staining of the ocular surface was done at each visit till the complete epithelialization of the AMG occurred. 


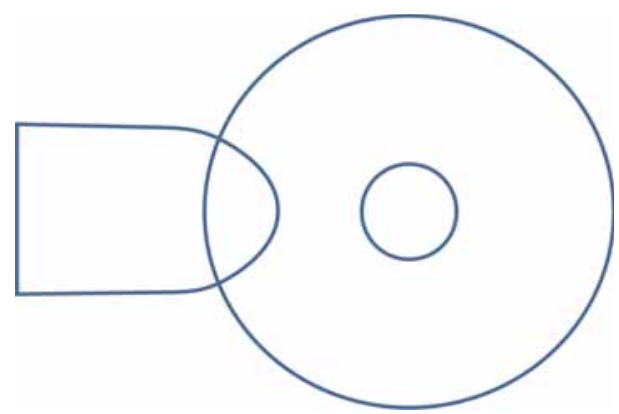

Fig. 1A: Bare sclera after pterygium excision

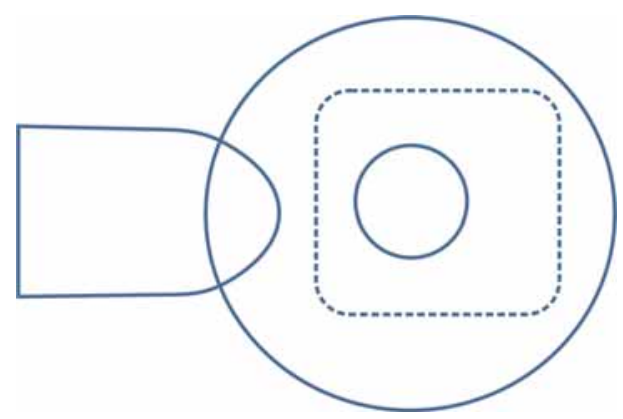

Fig. 1B: Amniotic membrane graft overlay

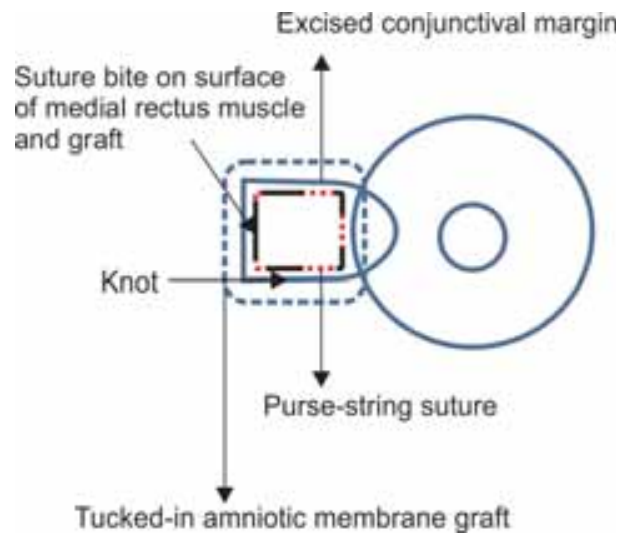

Fig. 1C: Purse-string suture for securing amniotic membrane graft after tucking it in (Black line: suture bites on the graft; Red line: suture bites underneath graft in the scleral tissue)

A recurrence was defined as a fibrovascular growth into the excised area crossing the limbus. The sutures were removed once the AMG epithelialized completely (at 3-4 weeks time).

\section{Statistical Analysis}

The data collected was analyzed using ' $t$ ' test and chi-square test to compare the recurrence rates of primary pterygium following two different techniques of AMT.

\section{RESULTS}

Group A included 24 eyes of 24 patients. The mean age was $38.29 \pm 12.60$ years (range $18-60$ years). Sixteen were male patients and 8 were females. The right eye was involved in 11 patients and the left eye in 13 patients. Group B comprised of 18 eyes of 18 patients. The mean age was $35.94 \pm 6.99$ years (range 25-47 years). There were 14 male patients and 4 females. Ten patients had their right eye involved and 8 patients had their left eye involved. The average length of pterygium on the cornea as measured on the slit-lamp was $2.79 \pm 1.10 \mathrm{~mm}$ (range 1.0-5.0 mm) in group A and $2.61 \pm 1.04 \mathrm{~mm}$ (range 1.0-5.0 mm) in group B. The average width of pterygium at the limbus was $4.67 \pm 1.17 \mathrm{~mm}$ (range 3.0-7.0 mm) in group A and $4.44 \pm 0.92 \mathrm{~mm}$ (range 3.0-6.0 mm) in group B. The mean follow-up period was $16.66 \pm 9.05$ months (range 12 to 38 months) for group A and $13.54 \pm 7.78$ months (range 12 to 35 months) for group B patients.

The outcome grading was done based on four representative grades as described by Prabhasawat et al. ${ }^{11}$ Grade 1 indicates a normal appearance of the operative site. Grade 2 indicates the presence of some fine episcleral vessels, but without any fibrous tissue in the excised area extending upto but not beyond the limbus. Grade 3 indicates the presence of additional fibrous tissue in the excised area without invading the cornea. Grade 4 represents a true recurrence with a fibrovascular tissue invading the cornea. The complete epithelialization of AMG occurred in 21 days (range 14 to 28 days) in group A (Fig. 2A) and 14 days (range 7 to 21 days) in group B (Figs $2 \mathrm{C}$ to E). In group A, 7 eyes $(29.17 \%)$ developed recurrence. In group B, 2 eyes (11.11\%) developed recurrence.

Variables such as age, sex, right/left eye, average length/ width of pterygium and epithelialization did not have any bearing on the recurrence rate of pterygium after two different techniques of human AMT ( $p$-value $>0.05$ ) as shown in Tables 1 and 2.

In group A, 4 eyes developed other complications. One patient developed infective keratitis which healed with a vascularized opacity after treatment with topical antibiotics. The second patient developed limbal thinning at the bed of the pterygium, which gradually healed with fibrous overgrowth on the cornea. Two patients had hemorrhage under the graft on the first postoperative day (Fig. 2B). The hematoma resolved during the subsequent follow-up without any deleterious effects. Apart from two recurrences, another complication that occurred in group B involved one eye which developed a hematoma under the AMG on the first postoperative day. It was gently expressed with a spatula with no further sequelae.

\section{DISCUSSION}

Pterygium is a fibrovascular growth onto the cornea from the conjunctiva for which a wide spectrum of treatment modalities has been tried. The main problem encountered after different techniques concerns the unpredictable rate and timing of recurrence. ${ }^{23}$ The aim of the surgical procedure is to have low recurrence rates and complications with a 
satisfactory cosmetic appearance following surgery. The human amniotic membrane contains a thick basement membrane and an avascular stromal matrix. ${ }^{24}$ The basement membrane facilitates migration of epithelial cells, reinforces adhesion of basal epithelial cells, ${ }^{25}$ promotes epithelial differentiation, ${ }^{26}$ and prevents epithelial apoptosis. ${ }^{27}$

AMG inhibits pterygium recurrence by promoting conjunctival wound healing and suppressing ECM production by pterygium fibroblasts. Other possible mechanisms include inhibition of inflammation by inhibiting chemokines expression by fibroblasts and interleukin-1 expression by epithelial cells, inhibition of neovascularization by inhibiting vascular endothelial cell growth, presence of anti-angiogenic/anti-inflammatory proteins, and protease inhibitors. Collectively, these actions explain why the amniotic membrane permits rapid epithelialization (i.e. generally complete in 2 to 3 weeks). ${ }^{11}$

\begin{tabular}{llll}
\multicolumn{4}{c}{ Table 1: Recurrence vs variables (group A) } \\
\hline Variables & $\begin{array}{l}\text { Degree of } \\
\text { freedom }\end{array}$ & $t$-value & $p$-value \\
\hline Age & 22 & 0.848 & 0.40557 \\
Sex & 1 & 0.0252 & 0.87387 \\
RE/LE & 1 & 0.0691 & 0.79265 \\
Length of pterygium & 22 & 0.585 & 0.56450 \\
Width of pterygium & 22 & 0.125 & 0.90166 \\
Epithelialization & 1 & 0.6588 & 0.41698 \\
\hline
\end{tabular}

Table 2: Recurrence vs variables (group B)

\begin{tabular}{llll}
\hline Variables & $\begin{array}{l}\text { Degree of } \\
\text { freedom }\end{array}$ & $t$-value & $p$-value \\
\hline Age & 16 & 1.954 & 0.06841 \\
Sex & 1 & 0.0100 & 0.92034 \\
RE/LE & 1 & 0.1826 & 0.66915 \\
Length of pterygium & 16 & 1.313 & 0.20770 \\
Width of pterygium & 16 & 1.833 & 0.08543 \\
Epithelialization & 1 & 0.1125 & 0.73732 \\
\hline
\end{tabular}
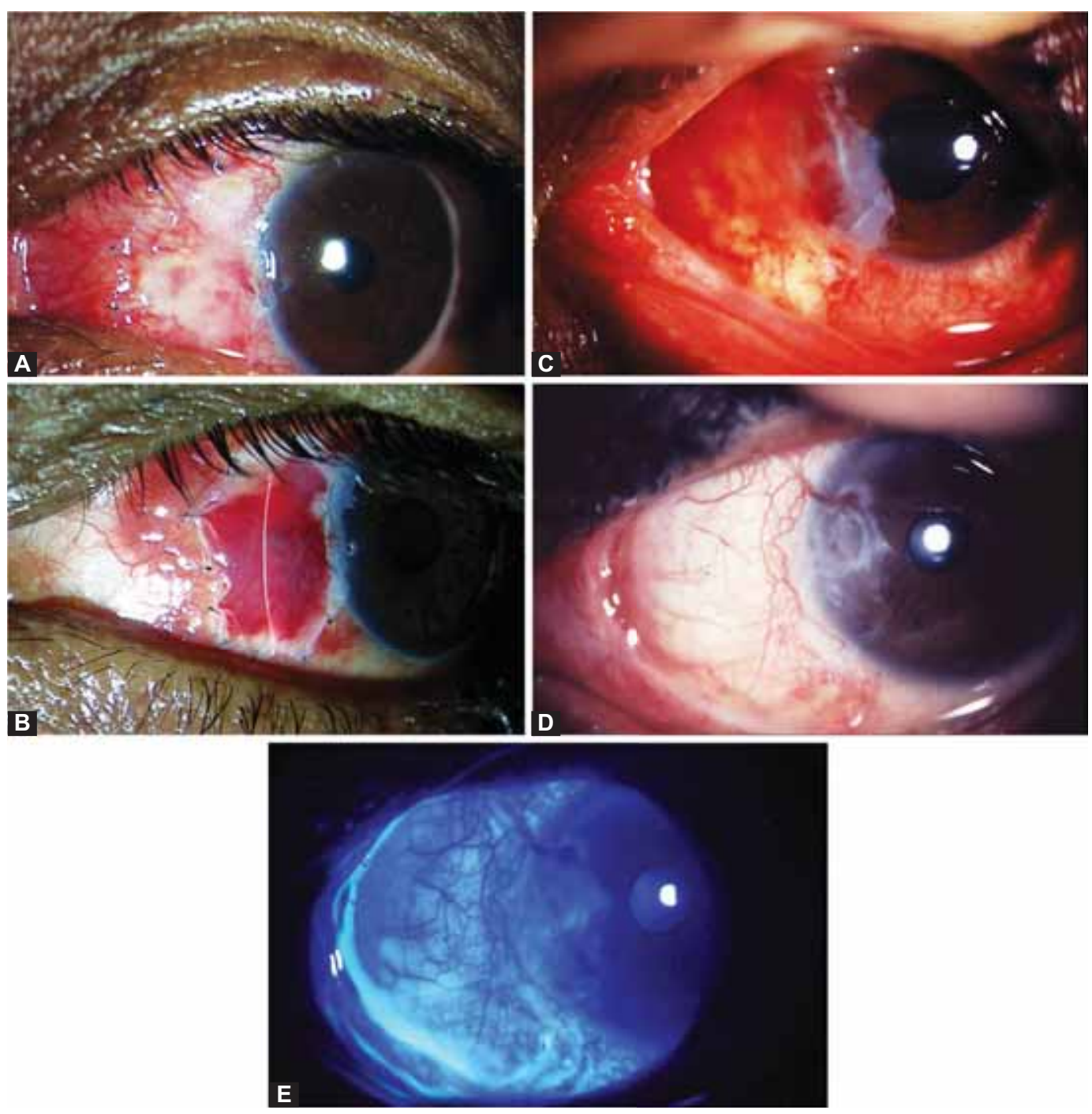

Figs 2A to E: (A) Persistent inflammation at 3 weeks follow-up after amniotic membrane transplantation by interrupted suture technique, $(B)$ hematoma under the amniotic membrane graft on first postoperative day following interrupted suture technique, $(C$ to $E)$ amniotic membrane graft in place on first postoperative day $(C)$, showing complete epithelialization at 3 weeks (D) as evident by fluorescein staining (E) in the purse-string suture group 
Solomon et al have evaluated the use of AMT after extensive removal of primary and recurrent pterygia and have found a recurrence rate of 3.0, 9.5 and $5.6 \%$ for primary, recurrent and all pterygia respectively at the end of a mean follow-up of 12.8 months. ${ }^{12}$ This is in contrast to an earlier report by Prabhasawat et al, ${ }^{11}$ which showed recurrence rate of 10.9 and $37.5 \%$ after AMT for primary and recurrent pterygia respectively. The improvement in outcome may have been due to extensive removal of the pterygium tissue, extending to the caruncle area a routine intraoperative injection of a depot corticosteroid and adjunctive postoperative injections in areas with apparent fibrovascular activity and inflammation. However, even when an extensive surgical excision was performed, it is still questionable whether the abnormal pterygium tissue had been completely removed, because no definite demarcation between inflamed fibrovascular tissue and normal conjunctiva could be made during surgery. Moreover, consideration should be given to the potential side-effects of long-acting corticosteroids. These are associated with increased intraocular pressure and should be avoided in patients with glaucoma. Since the extent of removal of fibrous tissue is highly subjective due to absence of demarcation of the margins of the pathology, this variability may have contributed to higher recurrence rates in our study.

AMT after excision of primary pterygium is indeed a safe, cosmetically acceptable and a technically less demanding procedure when compared to other modalities for the treatment of pterygium. Recurrences following pterygium excision and AMT have been attributed to the inadequacies of dissection and the absence of use of adjunctive depot steroids at the site of apparent increased fibrovascular activity (Solomon et al). ${ }^{12}$ Persistent inflammation following AMT has also been proposed to lead to recurrence by the same authors. Other factors such as fleshiness of pterygium, age of the patient and racial differences and the expertise of the surgeon have also been implicated in being responsible for higher recurrences.

Experience on the use of AMG with sutures or fibrin glue in pterygium surgery has been reported earlier by various authors. ${ }^{11-13,28-31}$ Recurrences from 3.0 to $37.5 \%$ have been reported from the use of amniotic membrane in pterygium surgery. ${ }^{11,12}$ Low recurrences have been claimed to be due to wide excision and the use of depot steroids. ${ }^{12}$ Present study documents higher recurrence rates than those reported by Prabhasawat et al. ${ }^{11}$ Kheirkhah et al assessed the surgical outcome in their patients in terms of postoperative conjunctival inflammation and other complications by comparing fibrin glue with sutures for securing AMG after performing an extensive removal of subconjunctival fibrovascular tissue and intraoperative application of
mitomycin-C. ${ }^{30}$ Although they found the occurrence of conjunctival inflammation significantly more common after sutures as compared to fibrin glue, the sutures used in their patients were interrupted, parallel-to-incision line nylon and vicryl sutures. We, on the other hand, have used a continuous, parallel-to-incision line, nylon purse-string suture.

When AMG is used in pterygium surgery with interrupted sutures, sometimes on the conjunctival side a gap is seen between the graft margin and the conjunctival host bed due to retraction of either graft margin or recipient conjunctival bed. In the presence of good apposition of the graft and adjacent conjunctiva, the epithelium heals readily and encourages rapid epithelial closure. In the purse string technique, we tucked the AMG under the surrounding recipient conjunctiva on three sides, starting at the limbus. As the edges of AMG are tucked under the conjunctiva, there is a continuous scaffold of the amniotic membrane basement membrane over which the conjunctival epithelium grows rapidly. This may have been the reason for rapid epithelialization of AMG. There is always some reparative inflammation following surgery. With this new technique, epithelialization was complete with in average of 14 days as compared to average of 21 days with interrupted sutures. Rapid epithelialization of AMG may help as a barrier against the tear derived inflammatory insults, thereby reducing the chances of inflammation or granulation tissue developing in the stroma.

Also there is only one knot of exposed suture in purse string suturing technique as compared to multiple knots in end to end suturing technique, thus causing more discomfort, irritation and inflammation with the end to end suturing technique. Sutures have been found to cause significantly more postoperative pain. ${ }^{32}$ This may be caused by an up regulated inflammatory process around the sutures during degradation. ${ }^{33}$ Conjunctival inflammation caused by sutures induces migration of Langerhans cells to the cornea. ${ }^{34}$ More severe inflammation may cause a higher recurrence rate, ${ }^{35}$ thereby associating suturing with a higher recurrence rate. This may explain lesser recurrence rate of $10.0 \%$ with purse string suture in comparison to $27.5 \%$ with interrupted suture technique, though it was statistically insignificant. The same technique of tuck-in cannot be used with conjunctival or conjunctivo-limbal grafts, because there is a risk of epithelial implantation cyst.

Correct suture placement incorporating episclera and adjacent conjunctiva is a time-consuming procedure and requires surgical skill and this can be avoided with use of purse string suture. However, certain problems related to suturing such as thin tissues cannot be overlooked. There may be a lack of proper apposition, hemorrhage, or buttonholes with suturing. Postoperative complications 
such as suture abscess, vascularization, ocular discomfort, inflammation, granuloma formation, tissue necrosis, and giant papillary conjunctivitis also need special attention. These problems are likely to be more with multiple exposed knots than with only one exposed knot with purse string suture. An ideal pterygium surgery would not only prevent recurrence but would be free of these complications.

We have earlier described the tuck-in technique of human AMT in pterygium surgery using fibrin glue. ${ }^{29}$ Epithelialization of the graft after using fibrin glue was much faster (7 days) in the study. ${ }^{29}$ The shortcomings encountered while using the sutures for securing the AMG can not be overlooked, especially when compared to fibrin glue technique. ${ }^{29,31}$ Moreover, our study suffers from limitations of being retrospective and nonrandomized. The surgical time was not documented. The number of patients in this series is small. However, in the settings where cost and availability of fibrin glue are limitations and an anaphylactic reaction to fibrin glue is a concern, the tuck-in technique of AMT by suturing is a good option. The advantage of using AMG is that it can restore large excised areas of pterygium when conjunctival autograft is not possible or conjunctiva is already scarred from previous surgery or has to be preserved for a possible glaucoma filtering surgery. ${ }^{12}$

\section{CONCLUSION}

Tucking of AMG and passing purse string sutures results in faster epithelization of AMG and lower recurrences in comparison to end to end suturing of $A M G$ in the management of primary pterygium.

To the best of our knowledge, the technique of human AMT by tuck-in method using purse string suture has not been described in literature. This method is a safe and simple modality of securing human AMG over the excised area of pterygium and having a low recurrence rate (11.11\%) with no significant intra- or postoperative complications. However, a larger prospective, randomized trial is required to further evaluate its merits.

\section{REFERENCES}

1. Singh G, Wilson MR, Foster CS. Mitomycin eye drops as treatment for pterygium. Am J Ophthalmol 1988;106:715-718.

2. Anduze AL, Burnett JM. Indications for and complications of mitomycin-C in pterygium surgery. Ophthalmic Surg Lasers 1996;27:667-673.

3. Cardillo JA, Alves MR, Ambrosio LE, Poterio MB, Jose NK. Single intraoperative application versus postoperative mitomycin $\mathrm{C}$ eye drops in pterygium surgery. Ophthalmology 1995;102:1949-1952.

4. Lam DS, Wong AK, Fan DS, Chew S, Kwok PS, Tso MO. Intraoperative mitomycin $\mathrm{C}$ to prevent recurrence of pterygium after excision: a 30-month follow-up study. Ophthalmology 1998;105:901-904.
5. Lewallen S. A randomized trial of conjunctival autografting for pterygium in the tropics. Ophthalmology 1989;96:1612-1624.

6. Mahar PS. Conjunctival autograft versus topical mitomycin C in treatment of pterygium Eye 1997;11:790-792.

7. Tan DTH, Chee SP, Dear KBG, Lim AS. Effect of pterygium morphology on pterygium recurrence in a controlled trial comparing conjunctival autografting with bare sclera excision. Arch Ophthalmol 1997;115:1235-1240.

8. Jap A, Chan C, Lim L, Tan DT. Conjunctival autorotation autograft for pterygium. An alternative to conjunctival autografting. Ophthalmology 1999; 106:67-71.

9. Mutlu FM, Sobaci G, Tatar T, Yildirim E. A comparative study of recurrent pterygium surgery: limbal conjunctival autograft transplantation versus mitomycin $\mathrm{C}$ with conjunctival flap. Ophthalmology 1999;106:817-821.

10. Lei G. Surgery for pterygium using a conjunctival pedunculated flap side. Br J Ophthalmol 1996;80:33-34.

11. Prabhasawat P, Barton K, Burkett G, Tseng SC. Comparison of conjunctival autografts, amniotic membrane grafts, and primary closure for pterygium excision. Ophthalmology 1997;104: 974-985.

12. Solomon A, Pires RT, Tseng SC. Amniotic membrane transplantation after extensive removal of primary and recurrent pterygia. Ophthalmology 2001;108:449-460.

13. Ma DH, See LC, Liau SB, Tsai RJ. Amniotic membrane graft for primary pterygium: comparison with conjunctival autograft and topical mitomycin C treatment. Br J Ophthamol 2000;84: 973-978.

14. Shimazaki J, Kosaka K, Shimmura S, Tsubota K. Amniotic membrane transplantation with conjunctival autograft for recurrent pterygium. Ophthalmology 2003;110:119-124.

15. Mackenzie FD, Hirst LW, Kynaston B, Bain C. Recurrence rate and complications after beta irradiation for pterygia. Ophthalmology 1991;98:1776-1781.

16. Schultz J, Hinrichs M, Kimmig B. Results of adjuvant radiation therapy after surgical excision of pterygium. Ger J Ophthalmol 1996;5:207-210.

17. Adamic AP, Starck T, Kenyon KR. The management of pterygium. Ophthalmol Clin North Am 1990;3:611-623.

18. Frucht-Perry J, Siganos CS, Ilsar M. Intraoperative application of topical mitomycin C for pterygium surgery. Ophthalmology 1996;103:674-677.

19. Helal M, Messiha N, Amayem A, el-Maghraby A, Elsherif Z, Dabees M. Intraoperative mitomycin $C$ versus postoperative topical mitomycin $\mathrm{C}$ drops for the treatment of pterygium. Ophthalmic Surg Lasers 1996;27:674-678.

20. Rubinfield RS, Pfister RR, Stein RM, Foster CS, Martin NF, Stoleru S, et al. Serious complications of topical mitomycin C after pterygium surgery. Ophthalmology 1992;99:1647-1654.

21. Dougherty PJ, Hardten DR, Lindstrom RL. Corneoscleral melt after pterygium surgery using a single intraoperative application of mitomycin C. Cornea 1996;15:537-540.

22. Dua HS, Azuar-Blanco A. Amniotic membrane transplantation. Br J Ophthalmol 1999;83:748-752.

23. Hirst LW, Seban A, Chant D. Pterygium recurrence time. Ophthalmology 1994;101:755-758.

24. Campbell S, Allen TD, Moser BB, Aplin JD. The translaminal fibrils of the human amnion basement membrane. J Cell Sci 1989;94:307-318.

25. Khodadoust AA, Silverstein AM, Kenyon DR, Dowling JE. Adhesion of regenerating corneal epithelium. The role of basement membrane. Am J Ophthalmol 1968;65:339-348. 
26. Kurpakus MA, Stock EL, Jones JCR. The role of the basement membrane in differential expression of keratin proteins in epithelial cells. Dev Biol 1992;150:243-255.

27. Boudreau N, Sympson CJ, Werb Z, Bissell MJ. Suppression of ICE and apoptosis in mammary epithelial cells by extracellular matrix. Science 1995;267:891-893.

28. Tekin NF, Kaynak S, Saatci AO, Cingil G. Preserved human amniotic membrane transplantation in the treatment of primary pterygium. Ophthalmic Surg Lasers 2001;32:464-469.

29. Jain AK, Bansal R, Sukhija J. Human Amniotic Membrane Transplantation with Fibrin Glue in Management of Primary Pterygia: A New Tuck- in Technique. Cornea 2008;27:94-99.

30. Kheirkhah A, Casas V, Sheha H, Raju VK, Tseng SC. Role of conjunctival inflammation in surgical outcome after amniotic membrane transplantation with or without fibrin glue for pterygium. Cornea 2008;27:56-63.
31. Ozer A, Yildirim N, Erol N, Yurdakul S. Long-term results of bare sclera, limbal-conjunctival autograft and amniotic membrane graft techniques in primary pterygium excisions. Ophthalmologica 2009;223:269-273.

32. Koranyi G, Seregard S, Kopp ED. Cut and paste: a no suture, small incision approach to pterygium surgery. Br J Ophthalmol 2004;88:911-914.

33. Biedner B, Rosenthal G. Conjunctival closure in strabismus surgery: vicryl versus fibrin glue. Ophthalmic Surg Lasers 1996;115:1235-1240.

34. Suzuki T, Sano Y, Kinoshita S. Conjunctival inflammation induces. Langerhans' cell migration into the cornea. Curr Eye Res 2000;21:550-553.

35. Ti SE, Tseng SCG. Management of primary and recurrent pterygium using amniotic membrane transplantation. Curr Opin Ophthalmol 2002;13:204-212. 